\title{
Sustainable Development in the Context of Major Infrastructure Projects in United Kingdom
}

\author{
Ebikapade Amasuomo1*, Syed Ali Hasnain², Ayodeji Yemi Osanyinlusi3 ${ }^{3}$ \\ ${ }^{1}$ School of Engineering and Built Environment (SEBE), Glasgow Caledonian University, Glasgow, UK \\ ${ }^{2}$ Centre of Excellence in Sustainable Building Design, School of Energy, Geosciences, Infrastructure \& Society, \\ Heriot-Watt University, Edinburgh, UK \\ ${ }^{3}$ School of Contemporary Sciences, University of Abertay Dundee, Dundee, UK \\ Email: ${ }^{*}$ ebiyoko@yahoo.co.uk
}

Received 4 May 2015; accepted 27 June 2015; published 30 June 2015

Copyright (C) 2015 by authors and Scientific Research Publishing Inc.

This work is licensed under the Creative Commons Attribution International License (CC BY). http://creativecommons.org/licenses/by/4.0/

(c) (7) Open Access

\begin{abstract}
The present paper is aimed at reviewing sustainable development and sustainability approach for infrastructure projects in the United Kingdom. It is imperative that major infrastructure projects (MIPs) adhere to the principles of sustainable development in order to promote sustainability. This requires identifying sustainable strategies that are capable of serving as a guide to inculcating sustainability into major infrastructural projects. The current paper examines ways of inculcating sustainability into infrastructure projects bearing in mind that construction, maintenance and the way we use facilities have significant impacts on the environment. In addition to the fact that, decision making tools on methods of inculcating sustainability into infrastructure project appear too complex to stakeholders; and in most cases they do not provide stakeholders the necessary information required to make a good judgement. Hence, the present paper relies on desk study to gather existing data on infrastructure project and sustainable development. Existing data are obtained from books, scholarly articles and the WebPages of municipal authorities in the UK. Amongst other findings, the paper reveals that the utilization of environmental impact statements and environmental assessment documents at the formative stage of projects will aid the assessment of the level of sustainability to be achieved in any infrastructure development.
\end{abstract}

\section{Keywords}

Sustainability, Infrastructure Projects, Sustainable Development

\footnotetext{
${ }^{*}$ Corresponding author.
} 


\section{Introduction}

Sustainable development is thus succinctly defined as the "development that meets the needs of the present without compromising the ability of future generations to meet their own needs" [1]. [2] defines and distinguishes between sustainable development and sustainability by defining sustainability as something that has the capacity for continuance; while [3] defines sustainability as a development which meets the basic principles of a sustainable development. His view is that sustainability is a push from sustainable to a more sustainable condition. Following the distinction drawn between both terms, [4] states that sustainable development is the process through which sustainability is attained. Drawing from this distinction, Forum for the Future, defines sustainable development as a dynamic process which enables all people to release their potentials and improve their quality of life in ways which simultaneously protect and enhance the Earth's life support systems. It must, however, be stated that there are various types of definitions for sustainable development depending on the perspective of the definers.

Some schools of thought have questioned the concept of sustainable development and even termed it, an inconsistent concept [5]. Some assert that the term sustainable development has been overused which has occasioned confusion and thus has no practical usefulness [6]. It has even been criticised for its purpose [7] and [8]. This write-up shall not engage in these controversies nor pursue the idea that it is more ethereal than concrete rather the Brundtland Commission and the forum for the future definitions shall be adopted and their underlying ideals shall guide the discussion herein. These definitions are adopted because they highlight the fact that a sustainable society thrives on people's ability to fulfil their potentials and enjoy high quality life in an environment where equity, fairness and justice prevail [9].

The tripod on which the ideals of sustainable development stand (which is illustrated in Figure 1) is the successful reconciliation of human beings environmental, social and economic demands [10].

In order to achieve social sustainability, the world requires responsible global citizens who will be ready to ensure that all social disruptions threatening human wellbeing and its environment are curtailed. There must be the feeling of ethical responsibility to stop human inequality, social injustice, war and poverty. The expression of sustainability issues in scientific and environmental terms is inadequate as implementing change is a social challenge that needs the enactment of laws both internationally and nationally as a means of social engineering in order to achieve sustainable urban planning and transport which will regulate local and individual lifestyles and ensure ethical consumerism [11]. In fact, the links between human rights and human development, corporate and environmental justice, and global poverty and citizen action transcend the economic issues of personal consumer and moral choice [12]. Compact urban cities reduce driving mileage which will lead to massive reduction of adverse environmental impacts from pollution in contrast to what is obtainable in sprawling cities [13].

Furthermore, sustainable use of materials for construction and production should be encouraged and toxic substances effectively controlled. Finally, effective waste management system should be designed. This could

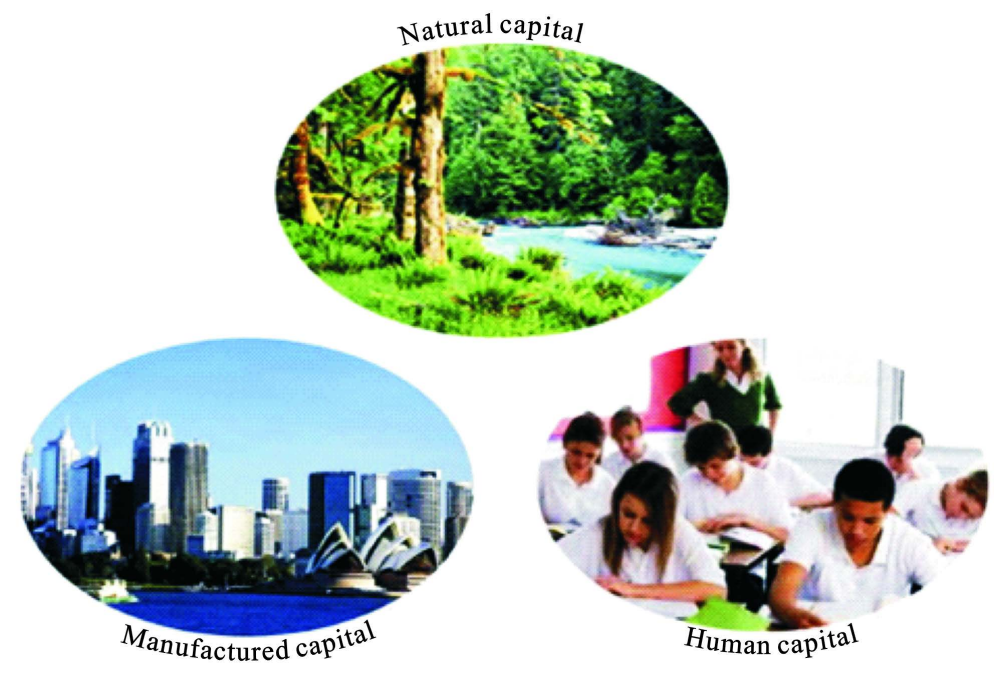

Figure 1. Components of sustainable development; Source; (3). 
be achieved by adhering to the waste management hierarchy and encouraging ethical consumerism [14]. In line with the agreement reached by governments of the world in 1992 as expressed in the Agenda 21 Plan which urged all countries to introduce a national strategy for sustainable development and the set target for its implementation in 2005, UK confirmed her commitment to the agenda in a white paper for International Development, 1997. In line with the UK national strategy for sustainable development and in consonance with the conclusions reached that local authorities had vital role to play in the realisation of the sustainable development ideals at the Rio de Janneiro and Johannesburg Earth's Summits, the Scottish Executive enacted the Scotland Local Government Act, 2003 which Section 1(5) imposed the duty of securing best values on local governments by mandating them to discharge their duties in a manner that would contribute to the achievement of sustainable development.

\section{Sustainable Development and Sustainability: Meaning and Distinction}

Sustainable development can be described as the sustenance of the delicate balance between economic growth and protection of environmental quality. It is a development that is hinged on a balance relationship between human activities in achieving economic and social development and the natural world. In essence, it is a development that encourages improvement of lifestyles and well beings by still preserving natural resources and the ecosystems. Sustainable development became an international policy concept in 1987 following the United Nations Brundtland Commission Report termed "Our Common Future". The Commission describes sustainable development as a process of change wherein the exploitation of resources, investments focus, the direction of technological development and institutional change are in tandem with the future as well as present needs.

Sustainable Development is thus succinctly defined as "the development that meets the needs of the present without compromising the ability of future generations to meet their own needs” [1]. It includes, by extension, the preservation of the environment for other species as well as human beings. The Commission concept of sustainable development is underpinned by a series of strategies imperatives which include: reviving growth; changing the quality of growth; meeting essential needs for jobs, food, energy, water, and sanitation; ensuring a sustainable level of population; conserving and enhancing the resource base; reorienting technology and managing risk; and merging environment and economics in decision making. Hence, Ashby 2015 concluded that in order to uphold the principles of sustainability; infrastructure development must maintain a balance between the environment, human development and economic prosperity as demonstrated in Figure 2.

The 2005 paper by Forum for the Future defines and distinguishes between sustainable development and sustainability by defining sustainability as the quality and sustainable as something that has the capacity for continuance. Brand, (2015) following the distinction between both terms as described above state that sustainable

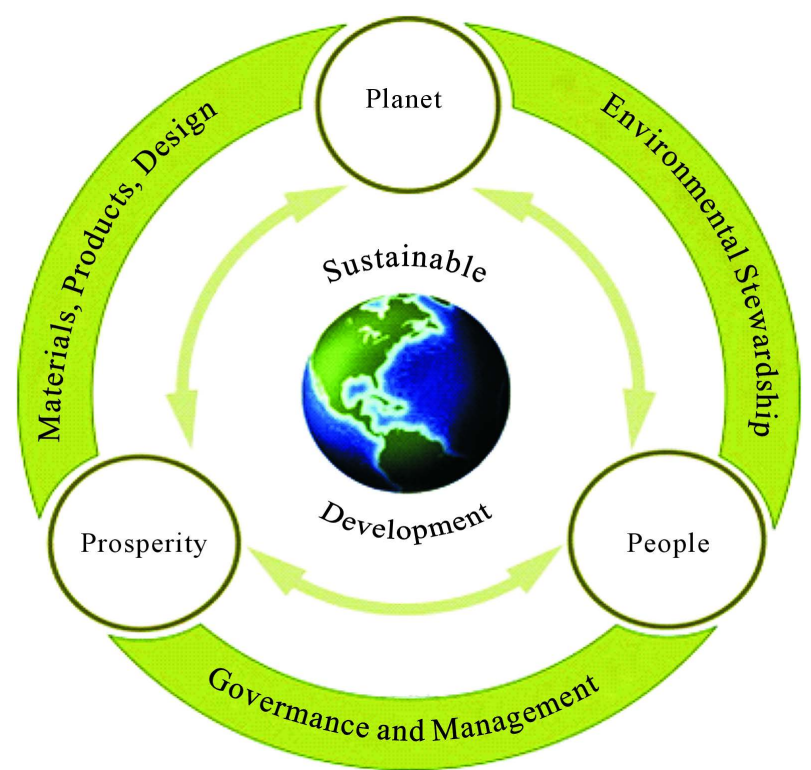

Figure 2. Sustainable development interaction; source; (3). 
development is the process through which sustainability is attained. Drawing from this distinction, Forum for the Future, defines sustainable development as a dynamic process which enables all people to release their potentials and improve their quality of life in ways which simultaneously protect and enhance the Earth's life support systems.

It must, however, be stated that there are various types of definitions for sustainable development depending on the perspective of the definers. In fact there are those that even question the whole concept of sustainable development and termed it as a bundle of contradictions. Some assert that the term sustainable development has been overused which has occasioned confusion and thus has no practical usefulness. It has even been criticised for its purpose. This write up shall not engage in these controversies nor pursue the idea that it is more ethereal than concrete rather the Brundtland Commission and the Forum for the Future definitions shall be adopted and their underlying ideals shall guide the discussion herein. These definitions are adopted because they highlight the fact that a sustainable society thrives on people's ability to fulfil their potentials and enjoy high quality life in an environment where equity, fairness and justice prevail.

\section{Pillars of Sustainable Development: Environmental, Social and Economic Demands}

The tripod on which the ideals of sustainable development stand is the successful reconciliation of human beings environmental, social and economic demands. These pillars are not mutually exclusive rather they are mutually reinforcing due to their overlapping nature. In fact, environmental limits can restrict the economic advancement of the society because sustainable development presupposes the improvement of the quality of human life within the carrying capacity of the ecosystems. The three pillars are discussed below in order to highlight human demands on them and situate them within the context of sustainable development by examining their interrelatedness.

\subsection{Economic Dimension: Demands and Sustainability}

The world exploding population coupled with its high consumption lifestyles necessitate the need for a sustainable economic strategy that will encourage and support fair distribution and efficient allocation of resources. This will ensure economic development that sustains a healthy balance with the ecosystem. This is germane because human beings all over the world perceive material consumption as a source of pleasure while their economic activities have adverse effects on the social and environmental sustainability of the world and they invariably neglect their responsibility as the stewards of the earth. Though, it could be argued that environmental and ecological variables and issues are basic, they are still part of a multidimensional perspective that require social, cultural, monetary and finance to be integrated into sustainability analysis. Sustainability as a concept surpasses the economic concepts of sustained yields, resources or profit margin.

Therefore, with the increasing population and unsustainable levels of human consumption, the need arises for the development of strategies and technologies that will support economic growth which is devoid of environmental damage and wasteful resource depletion.

\subsection{Social Dimension: Achieving Social Sustainability}

In order to achieve social sustainability, the world requires responsible global citizens who will be ready to ensure that all social disruptions threatening human well-being and its environment are curtailed. There must be the feeling of ethical responsibility to stop human inequality, social injustice, war and poverty. The Rio conference in 1992 points out that, the expression of sustainability issues in scientific and environmental terms are inadequate as implementing change is a social challenge that needs the enactment of laws both internationally and nationally as a means of social engineering in order to achieve sustainable urban planning and transport which will regulate local and individual lifestyles and ensure ethical consumerism.

In fact, the link between human rights and human development, corporate and environmental justice, global poverty and citizen action transcend the economic issues of personal consumer and moral choice. A comprehensive strategy for a sustainable social system focused on the advancement of peace, security and social justice which will promote social equality should be devised. Such system will seek to improve the standard of education, ensure political parity of genders, bridge the gap between the rich and the poor and support intergenerational equity. 
A veritable strategy is the encouragement of sustainable living in human settlements by creating self-reliant communities that thrive on self-sufficiency through simple living. This idea of simple living will by extension forms the foundation of bioregional economy. Similarly, a new urbanism approach could be adopted. This involves the altering of built environment by making it compact in an effort to establish and preserve sustainable cities through sustainable transportation. Compact urban cities reduce driving mileage which will lead to massive reduction of adverse environmental impacts from pollution in contrast to what is obtainable in sprawling cities.

The ultimate aims will be to discourage the treatment of nature as mere commodity to be exploited unchecked and encourage large scale social movements such as eco-municipalities which is participatory with foundation on sustainability principles as it is practised in major cities and town in both Sweden and America [15].

\subsection{Environmental Dimension: Finite Resources and Consumer Demands}

The tension between human consumption and the preservation of a healthy ecosystem underpin the philosophy for sustainable developments. There is need for effective environmental and natural resources management coupled with regulated human consumption in order to curtail the negative human impacts and improve ecosystem services.

The management of the Environment and natural resources involve the maintenance of the earth's atmosphere by assessing all aspects of the carbon cycle in order to devise means of addressing the issue of human induced climate change so as to avert the likely catastrophic effects it would have on biodiversity and the environment. Similarly, strategy must be put in place to safeguard the environment from air pollution in the cities. The oceans are to be protected. Effective coastal management that will control over fishing, coral bleaching, ocean acidification; The sea level rising and ensure that oceans are not turned into dumping ground for human waste is required. In the same vein, freshwater crisis need to be avoided as increasing urbanisation tends to cause pollution of clean water supplies with the fast declining rate of biodiversity rich water ecosystems [16].

The preservation of the forests and maintenance of their conditions for the mitigation of emissions and protection of the ecosystems should also be part of a global strategy for natural resources management [17]. In addition sustainable agriculture should be encouraged and effective conservation system to protect species should be in place. Overall, land use must be done in a way that will boost major sustainability benefits through the pursuit of green cities and towns.

Consequently, environmental sustainability is achieved by effective management of human consumption and utilisation of the ecosystem services. In meeting the key human needs of food, energy, water and materials efforts should be made in making the full cycle of production, use and disposal sustainable. Energy demand should be met with an aim of reducing greenhouse emissions by exploring renewable energies and making less carbon emitting technology and transportation systems which will encourage carbon neutral lifestyles for individuals and communities. Water efficiency improvement should be sought on global scale by increased demand management and food demand through sustainable agriculture and organic farming. Furthermore, sustainable use of materials for construction and production should be encouraged and toxic substances effectively controlled. Finally, effective waste management system should be designed. This could be achieved by adhering to the waste management hierarchy and encouraging ethical consumerism (Brower \& Leon, 1999).

These wide sustainability objectives need to be inculcated in a narrower way into infrastructural projects in furtherance of a country's sustain development strategy. This imposes the challenges of including the sustainability objective on authorities responsible for planning the delivery of the infrastructural project. The inculcation of these wider sustainability objectives into major infrastructural projects is the fulcrum of this paper.

\section{Sustainability: The United Kingdom Approach}

In line with the agreement reached by governments of the world in 1992 as expressed in the Agenda 21 Plan which urges all countries to introduce a national strategy for sustainable development (NSSD) [18] and the set target for its implementation in 2005, UK confirmed her commitment to the agenda in a white paper for International Development in 1997. UK subsequently set out four core objectives to actualise its sustainable development strategy in policy paper termed; a better quality of life wherein the objectives are laid out

- Social movement that takes cognisance of the needs of everyone.

- Effective protection of the environment. 
- Prudent use of the natural resources.

- Maintenance of high and stable levels of economic growth and employment.

This was later built upon to develop a new framework for sustainable development that prescribes a balance between economic growth and preservation of the environment and to encourage practices that will boost awareness of issues related to sustainable development which will lead to proper decision. All the members of the administrative bodies i.e. England, Wales, Scotland and Northern Ireland, within the Kingdom are urged to pursue the ideals of sustainable development independently though, by integrating the five shared principles which form the fulcrum of the sustainable development strategy in UK. The five shared principles on which the sustainable strategy is based are:

- Living within the environmental limits.

- Ensuring a strong, health and just society.

- Promoting good governance.

- Using sound science responsibly.

- Attaining a sustainable economy [19].

\section{Major Infrastructural Projects and Construction}

Infrastructure is defined as the basic physical and organisational structures require for the operation of a society or enterprise (Online Compact Oxford Dictionary). It is the essential services and facilities that form an integral part of a nation's development and enhance the smooth running of an economy. Some examples of major infrastructure projects are demonstrated in Figure 3 [20]. [21] pointed out that due to the scale and importance of many infrastructure projects, long term economic growth may be hampered when infrastructures are allowed to deteriorate. A project may be described as a major infrastructure project if it is large scale, of great local, regional or national importance and provide basic facilities, services in support of the functioning of a society [22]. Infrastructure projects are normally delivered through large scale construction processes. Yet every construction will not pass for infrastructure project. The construction of drainage or transportation network in support of commercial and residential housing as part of urban city development cannot be considered as infrastructure project. The distinction between infrastructure project and mere building construction are not only in the nature, diversity, form, and function of the project involved or the difference in standards and practices employed in the design and construction but also in the spatial scale involved in infrastructure projects.

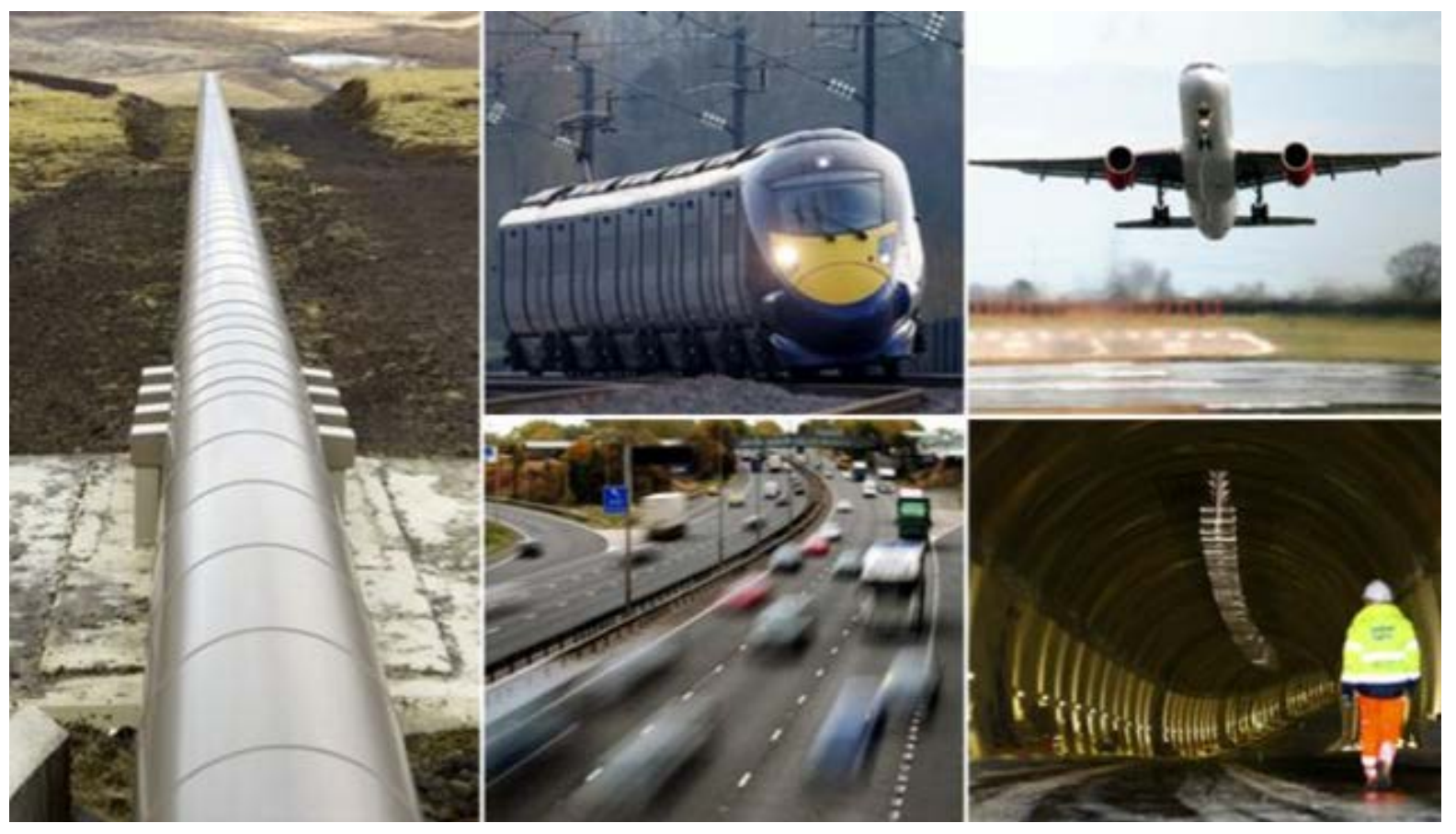

Figure 3. Major infrastructural projects; Source (BBC, 2013). 
The spatial scale of infrastructure projects coupled with the huge risks of direct degradation of natural resources associated with construction processes makes planning an essential part of realising government policies on sustainable development. Countries such as United Kingdom have developed a planning system that will underpin sustainable growth and development by regulating all development schemes. In 2004, the UK enacted the Planning and Compulsory Purchase Act which marks the start of a sustainable revolution. The Act established a new spatial planning system that has sustainable development as its fundamental aim in addition to controlling land uses and building mass. This marks a paradigm shift from the traditional land use planning system due to its integration of policies for development and use of land with other crucial policies and programmes that enhance sustainable goals.

The Act, further, provides for new modalities for the creation and delivery of spatial plan and policies in the different levels of governance. At the central government level, it imposes the duty of creating an overarching framework for planning policy by articulating a Planning Policy Statement (PPS) which will outline sustainability related strategy regulations and guidance. While at the regional level, there is provision for Regional Spatial Strategies (RSS) and local levels have Local Development Frameworks which will underpin the development plan for each council area (the Planning and Compulsory Purchase Act, 2004 as amended by the Planning and Compulsory Purchase Act 2008) It must be stated that the 2008 has substantially modified the provisions of the 2004 Act, the amendments and alterations do not substantially affect this position and it( the provisions in the 2004) is deemed apposite for the purpose of our discussion herein.

\section{Sustainability: Decision Making Criteria, Indicators and Assessment}

\subsection{Decision Making Process}

The integration of sustainability into the planning framework of infrastructure project imposes issue of choices on the authorities saddled with the responsibility of planning, designing and developing the project. Some fundamental decision need to be made at the early stage of the project yet the objectives of sustainability is considered vague in most cases [23]. The task of choosing the best out of multiple alternatives becomes exacerbated due to the fact that they are not only considering the technical aspect of a project but the technicalities must be considered together with the project environmental, economic and social implications [24].

The decision has to be made in spite of many uncertainties and complexities in understanding the behaviour of ecosystems [25] and a wrong choice could occasion serious or irreversible damage to the environment. Similarly, the long time frame between the conception of a project and its development leaves room for changes to occur as new knowledge gain overtime may adversely impact on an earlier decision and alter its cause effect relationship (Rauch, 1998). In the same vein, the unpredictable nature of public response may make social inclusion a bit difficult. This is coupled with the fact that the public are sometimes reluctant to participate in decision making due to expert dominance, conflict and lack of credibility of the process [26]. This could adversely affect decision making as public participation is an essential ingredient in achieving sustainable development (Rio, 1992; Agenda 21; Aarhus, 1998). Finally, sustainability concept is highly dynamic and largely indefinite due to its progressive quality and conflicts in stakeholders' perceptions and interests [27]. Bearing the concept of sustainability in mind [28] argued that some major key factor to be considered in decision making includes; upholding high environmental quality and the satisfaction of citizens.

As a result of this, a dynamic strategy which will be flexible enough to adjust itself to the anticipated changes and adapt to the complexities in decision making is proposed. The strategy should incorporate public participation at every stage of decision making with modality for promoting increase knowledge of sustainability in the public through simple and clear model of raising their awareness; encouraging debate without imposing solutions; creating a common ground for different stakeholders to contribute their ideas in an uncomplicated manner; creating room for practical implementation, encouraging communication and thinking on issues of sustainability and encouraging consideration of issues that could adversely affect sustainable development in relation to the project under consideration [29]. In essence the project sustainability criteria must be well articulated and indicators for it assessment well defined.

\subsection{Criteria and Indicators}

There is a need to make the right decisions at the initial stages of the project as the authorities are faced with 
numerous alternatives. This is important for ease of sustainability assessment, which must be transparent, comprehensive, integrated and farsighted, by decision makers. The underlying principles which are the expression of the goals and objectives of the sustainable development plan for the project must be set out. This is termed the criteria. The criteria connect the principles to the project by articulating the qualities the project shall possess via the principles cum objectives. The criteria comprise a series of factors characterising the project by which sustainability can be assessed. Each of the identified criteria will be associated with a series of specific indicator that is used to evaluate change.

There is, however, a need to clarify the relationship and distinction between criteria and indicators. Both terms have been muddled up in some literature and the terms erroneously used interchangeably [30]. For our purpose, criteria are identified factors, benchmarks or the objectives that sustainable development seeks to achieve. Indicators are the quantitative or descriptive (qualitative) parameters that can be used to observe, measure and assess trends as the criteria change. They, indicators are judgmental values that aid the decision making authorities to clarify, simplify, measure and communicate the complex, uncertain and multi-dimensional issues involved in sustainable decision making to the people [31]. Agenda 21 prescribes the use of indicators which depict the current state of the economy, environment and society to evaluate the sustainability of a plan. Multiple indicators could be employed to evaluate a single criterion and in order to establish whether a project is sustainable, each criterion and indicators must be evaluated together with others, never separately. Indicators are the most important tools of measuring the compliance of a project with the sustainable development criteria (LGMD, 1995). They are essential to decision makers in the process of tailoring a project in line with the dynamic changes in order to meet its sustainability aims (Agenda 21).

Numerous sustainable development indicators have been developed to assess, monitor and explain in a clearer way the outcome or intended outcomes of sustainable development policies. The UN Commission on Sustainable Development (CSD) after reviewing a list of about 134 indicators that were pre developed to aid national policy formulation on sustainable development, came up with 58 indicators which are underpin by about 15 themes and various sub themes such poverty, natural resources consumption, climate change and availability of relevant information to the general public. The Organisation for Economic Co-operation and Development (OECD) and the International Institute of Sustainable Development (IISD) have also developed similar indicators which will provide the policy makers and the public the basis of judging the progress of sustainable development objectives.

The United Kingdom developed 20 headline indicators based on shared priorities across UK and a further 48 non framework indicators to monitor and evaluate its National Strategy for sustainable development through comparison of yearly data generated by the different monitoring agencies. The framework indicators are relevant for Scotland and other union government. The results of the shared framework indicators will be collected and reported by the UK government, all the union governments also have their own set of indicators. There is also the need to develop sustainable development indicators at the local level as suggested by the Local Agenda 21.

As noted earlier, there are different forms of indicators. It could be quantitative (nominal variable or quantitative (ordinal) variable. The choice of indicators depends on the kind of information available; means of obtaining it and the attribute/relevance of the indicator to the development it is to be applied [32]. The difference foster the issue of choice of the decision makers The decision makers may decide to adopt quantitative indicators when there are available project can be assessed or adopt the quantitative indicators which will rely on the perception of stakeholders. It must be noted that developing sustainable development indicators has its own challenges such as the problem of determining the dimensions of its application, the relevant scale of measure, weights to be attached to individual observations, the margin of error and the robustness of the indicators.

However, whatever choice of indicator that is adopted indicator must satisfy certain criteria which will enable them to make good choices. [33] enumerate the underlying qualities of an indicator that would aid decision makers and public in making good choices as follows: it should be acceptable to the public and all stakeholders; it should not conflict with the international, regional and national indicators of sustainable development; it should be for something measurable or obtainable; it should be clear and easy to understand; it should relevance to the goals of sustainable development by rating to the sustainability criteria; it should have a reasonable financial, human and technical means of developing and monitoring.

\section{Evaluating Sustainability Multiple Criteria: The Decision Tools}

Decision making and decision making tools are fast becoming an integral part of today's society. Although sev- 
eral technologies are available today to decision makers, without human input, technologies alone might not deliver expected results. Consequently, several tools have been developed to aid in decision making process; one of such tools is the multi criteria decision making tool [34]. During the early stage of projects, several interests are brought to bear at the same time. Multi criterion decision tool assist stakeholders to arrive at an appropriate decision which considers the various interest of the project [35]. This decision making tools aid policy makers and decision makers to satisfy the economic, social and environmental indicators in the early phrase of a project as illustrated in Figure 4.

Sustainable development is the reconciliation of the environmental, social and economic demands of a society in order to improve the quality of human life within the carrying capacity of the ecosystems. The different facets of sustainability require that multiple criteria will be adopted. This requires that the various alternative criteria must be evaluated against one another to choose those criteria that could be grouped together in achieving the sustainability objectives of the project. This evaluation requires the aid of decision tools.

[36] acknowledge the use of efficient multi criteria tools in deciding the best criteria that would be adopted together that will align the environmental, social, economic and technical objectives of a project to achieve its sustainability objectives. There are two types of multiple criteria tools in line with the methods adopted in reconciling the conflicting objectives of the different criteria in achieving the sustainable development goal. They are multi attribute and multi objective tools [37] [38]. Zanakis et al. describe multi objective tools as the tools to be adopted where there are no alternative criteria but the numerous objectives of the project are coordinated to overcome limitations in order to arrive at the most satisfactory solution. On the other hand Pohcker, describes multi attribute as the tools to be adopted in decision making when there are various alternatives to chosen from and be grouped together for the realisation of a common goal i.e. sustainable development.

The multi attribute tools is most appropriate to the present discussion and its common variants are: The weighted sum method (WSM); Weighted Product Method (WPM); Analytical Hierarchy Process AHP); Multi Attribute Utility Theory (MAUT); Elimination of Choice Translating Reality (ELECTRE); Preference Ranking Organisation Method for Enrichment Evaluation (PROMETHEE) and Compromise Programming (CP)

\section{Evaluating Sustainability in Project: An Assessment Tools}

A comprehensive project assessment with respect to its sustainability requires the evaluation and comparisons of development alternatives. It is, however, difficult to integrate sustainability assessment into environmental documents at the single project level owing to lack of laws that explicitly require that sustainability should be a criterion for assessment and the tendency to over-estimate the direct consequences of construction and operation of the project while neglecting to take into cognisance the indirect and cumulative effects of the project. More so, some of the assessment tools are either useful in assessing a facet of sustainability or inadequate for assessing multi projects. [39] argue that although several assessment tools are deployed to evaluate the sustainability of a project; continuous assessments are however more effecting in order to ensure that projects meets set objectives. Assessment tools such as Building Research Establishment (BRE) Environmental Assessment method

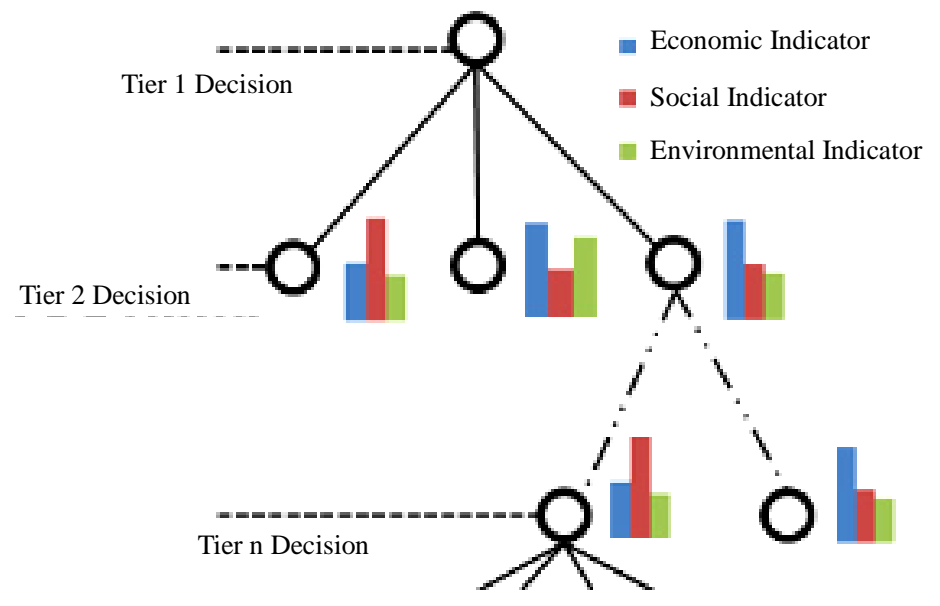

Figure 4. Incorporating sustainability in decision making; Source (35). 
(BREEAM) and Civil Engineering Environmental Quality Assessment and Award (CEEQUAL) have as their common problem environmental bias. They do not lay significant emphasis on the social and economic impacts of a project nor admit of the inclusion of project level and local specific criteria in their evaluation. Similarly, the sustainable Project Appraisal Routine (SPeAR) tool which was developed by Ove Arup to monitor the sustainability of a project in its life span is also inadequate due to its inadaptability to multi project and lack of guidelines to improve identified weak area during assessments [40]. The Sustainable Water Industry Assets Resource Decision (SWARD) projects outlines seven stages of assessing the sustainability of water project [41], it is however, too project specific and will need considerable modification for its successful application into other infrastructure project besides water.

The assessment of the sustainability of an infrastructure project should be based on the incorporation of simple sustainability criteria and indicators into Environmental Impact Statements and Environmental Assessment of projects with the analysis of their relationship to the Cumulative Effect Assessment trend of the projects [42].

Although, there are new assessment tools for the evaluation of sustainability of an infrastructure project, this thesis shall limit its discussion to the tools discussed above as the other new tools suffer the same defect identified by Robert Senner.

\section{Conclusion}

Environmental degradation presents major concern around the world today as population increase and economic development threaten the earth's resources. Hence, nations around the world are responding with policies on sustainable development with the aim of maintain a balance between economic growth and protection of environmental quality; in order to improve the life styles and well-being of the people. Sustainability is a concept that is incapable of a precise definition although its objectives are well understood. This paper discusses sustainable development and distinguishes it from sustainability. It highlights the three pillars on which sustainability stands and examines the UK approach to realising the objectives of sustainable development. Inculcating sustainability into infrastructure projects requires decision makers to assess alternatives and formulate criteria and sub criteria; with the intention of observing, monitoring and assessing projects compliance level with the principles of sustainability. Formulating criteria and development of indicators are not without its challenges especially with the public involvement in the decision making process. The various decision making tools appear too complex and do not provide the stakeholders the necessary information required to make good judgement. The assessment tools in the construction industry are found to be inadequate. However, the utilization of environmental impact statements and environmental assessment documents at the formative stage of projects will aid the assessment of the level of sustainability that can be achieved by a project.

\section{References}

[1] World Commission on Environment and Development (1987) Our Common Future. Oxford University Press, Oxford.

[2] (2005) Forum for the Future 2005, Ten Years of Transformation. Annual Report 2006 Reporting on January-December 2005 Registered Office: Overseas House, 19-21 Ironmonger, Row, London ECIV 3QN. Registered Charity Number 1040519.

[3] Ashby, M.F. (2015) Background, in: Materials and Sustainable Development. Elsevier, 1-25. http://linkinghub.elsevier.com/retrieve/pii/B9780081001769000013

[4] Brand, K.-W. (2015) Sustainable Development. International Encyclopedia of the Social \& Behavioral Sciences (Second Edition), 812-816. http://www.sciencedirect.com/science/article/pii/B9780080970868910948

[5] Dovers, S.R. and Handmer, J.W. (1993) Contradictions in Sustainability. Environmental Conservation, 20, $217-222$. http://dx.doi.org/10.1017/S0376892900022992

[6] Temple, Stanley, Interview Remarks (1992) Old Issue, New Urgency? Wisconsin Environmental Dimension, 1, 1.

[7] Aguirre, M.S. (2002) Sustainable Development: Why the Focus on Population? International Journal of Social Economics, 29, 923-945. http://dx.doi.org/10.1108/03068290210447978

[8] Anderson, M.J. (2002) Sustainable Development. WFF Voices Online Edition, Vol. XVII, 1.

[9] Parkin, S. (2000) Sustainable Development: The Concept and the Practical Challenge. Proceedings of the Institution of Civil Engineers, Civil Engineering, 138, 3-8.

[10] UNGA (United Nations General Assembly) (2005) 2005 World Summit Outcome, Resolution Adopted by the General 
Assembly. http://data.unaids.org/Topics/UniversalAccess/worldsummitoutcome_resolution_24oct2005_en.pdf

[11] United Nations Division for Sustainable Development, n.d. United Nations Conference on Environment \& Development Rio de Janerio, Brazil, 3 to 14 June 1992 AGENDA 21 [WWW Document].

https://sustainabledevelopment.un.org/content/documents/Agenda21.pdf

[12] Blewitt, J. (2008) Understanding Sustainable Development. Earthscan, London, 21-24.

[13] Ewing, R., Bartholomew, K., Winkelman, S., Waters, J., Chen, D., McCann, B. and Goldbert, D. (2007) Growing Cooler-The Evidence on Urban Development and Climate Change. Urban Land Institute, Smart Growth America, the Center for Clean Air Policy, and National Center for Smart Growth, Washington DC and College Park. http://docs.nrdc.org/cities/files/cit_07092401a.pdf

[14] Brower, M. and Leon, W. (1999) The Consumer's Guide to Effective Environmental Choices: Practical Advice from the Union of Concerned Scientists. Three Rivers Press, New York.

[15] James, S. (2003) Eco-Municipalities: Sweden and the United States: A Systems Approach to Creating Communities.

[16] Clarke, R. and King, J. (2006) The Atlas of Water. Earthscan, London.

[17] IPCC (2006) IPCC Guidelines for National Greenhouse Inventories, Volume 4, Agriculture, Forestry, and other Land Uses. Institute for Global Environment Strategies, Hayama.

[18] UNCED (1992) Agenda 21. United Nations Conference on Environment and Development (UNCED), United Nations General Assembly, New York.

[19] DEFRA (2005) Securing the Future—Delivering UK Sustainable Development Strategy [WWW Document]. https://www.gov.uk/government/uploads/system/uploads/attachment_data/file/69412/pb10589-securing-the-future-050 307.pdf

[20] Sullivan, A. and Sheffrin, M.S. (2003) Economics: Principles in Action. Pearson Prentice Hall, Upper Saddle River.

[21] Cook, P. and Stevens, J. (1992) An End-User Approach to the Measurement of Performance of Capital in an Environmental Context in Asia. World Development, 20, 541-555. http://dx.doi.org/10.1016/0305-750X(92)90043-U

[22] Parliamentary Office of Science and Technology (2002) Appraising Major Infrastructure Projects. (WWW Document) http://www.parliament.uk/documents/post/pn173.pdf

[23] Bruner, N. and Starkl, M. (2004) Decision Aids Systems for Evaluating Sustainability: A Critical Survey. Environmental Impact Assessment Review, 24, 441-469.

[24] Rauch, W. (1998) Problems of Decision Making for a Sustainable Development. Water Science \& Technology, 38, 3139. http://dx.doi.org/10.1016/S0273-1223(98)00637-4

[25] Chechile, R.A. and Carlisle, S. (1991) Introduction to Environmental Decision Making: A Multi-Disciplinary Perspective. Van Nostrand Reinhold, New York.

[26] Sheppard, R.J. and Meitner, M. (2005) Using Multi-Criteria Analysis and Visualisation for Sustainable Forest Management Planning with Stakeholder Groups. Forest Ecology and Management, 207, 171-187. http://dx.doi.org/10.1016/j.foreco.2004.10.032

[27] Mog, J.M. (2004) Struggling with Sustainability: A Comparative Framework for Evaluating Sustainable Development Programs. World Development, 32, 2139-2160. http://dx.doi.org/10.1016/j.worlddev.2004.07.002

[28] Wang, H., Shen, Q., Tang, B., Lu, C., Peng, Y. and Tang, L. (2014) A Framework of Decision-Making Factors and Supporting Information for Facilitating Sustainable Site Planning in Urban Renewal Projects. Cities, 40, 44-55. http://dx.doi.org/10.1016/j.cities.2014.04.005

[29] Brandon, P.S. and Lombardi, P. (2005) Evaluating Sustainable Development: In the Built Environment. Blackwell Science, Oxford.

[30] Sahely, H.R., Kennedy, C.A. and Adams, B.J. (2005) Developing Sustainability Criteria for Urban Infrastructure Systems. Canadian Journal of Civil Engineering, 32, 72-85. http://dx.doi.org/10.1139/104-072

[31] Moffat, I., Hanley, N. and Wilson, M.D. (2001) Measuring and Modelling Sustainable Development. Parthenon, New York.

[32] Moldan, B. and Billharz, S., Eds. (1997) Sustainability Indicators: Report of the Project on Indicators of Sustainable Development. John Wiley, Chichester.

[33] Rice, J.C. and Rochet, M.-J. (2004) A Framework for Selecting a Suite of Indicators for Fisheries Management. ICES Journal of Marine Sciences, 62, 516-527. http://dx.doi.org/10.1016/j.icesjms.2005.01.003

[34] Abdullah, L. (2013) Fuzzy Multi Criteria Decision Making and Its Applications: A Brief Review of Category. ProcediaSocial and Behavioral Sciences, 97, 131-136. http://dx.doi.org/10.1016/j.sbspro.2013.10.213

[35] Buchert, T., Neugebauer, S., Schenker, S., Lindow, K. and Stark, R. (2015) Multi-Criteria Decision Making as a Tool 
for Sustainable Product Development—Benefits and Obstacles. Procedia CIRP, 26, 70-75.

[36] Antunes, P., Santos, R. and Vedeira, N. (2004) Participatory Decision Making for Sustainable Development: The Use of Metdiated Modelling Techniques. Land Use Policy. Article in Press.

[37] Pohckar, S.D. and Ramachandran, M. (2004) Application of Multi-Attribute Decision Making to Sustainable Energy Planning-A Review. Renewable and Sustainable Energy Reviews, 8, 365-381. http://dx.doi.org/10.1016/j.rser.2003.12.007

[38] Zanakis, S.H., Solomon, A., Wishart, N. and Dublish, S. (1998) Multi-Attribute Decision Making: A Simulation Comparison of Select Methods. European Journal of Operational Research, 107, 507-529. http://dx.doi.org/10.1016/S0377-2217(97)00147-1

[39] Laprise, M., Lufkin, S. and Rey, E. (2015) An Indicator System for the Assessment of Sustainability Integrated into the Project Dynamics of Regeneration of Disused Urban Areas. Building and Environment, 86, 29-38. http://dx.doi.org/10.1016/j.buildenv.2014.12.002

[40] Bostock, A. (2005) Sustainable Decision Making in the Water Industry. Unpublished Master's Thesis, University of Abertay, Dundee.

[41] Ashely, R., Blackwood, D., Buiter, D. and Jowitt, P., Eds. (2004) Sustainable Water Services. IWA Publishing, London.

[42] Senner, R. (2008) Assessing the Sustainability of Projects Alternatives: An Increasing Role for Cumulative Effect Assessments.

http://www.iaia.org/iaia08calgary/documents/Assessing\%20the\%20Sustainability\%20of\%20Project\%20Alternatives.p $\underline{\mathrm{df}}$ 